Este artigo pretende, com base nas concepções depreendidas da psicanálise sobre discurso e sujeito, discutir a função da literatura, principalmente quando se a propõe como atividade nas escolas. Após afirmar que a literatura se diferencia da ciência exatamente porque ela, ao contrário desta segunda, assume-se como discurso, caminho para a conclusão de que, ao tomar a literatura pela lente dos chamados métodos de ensino, a escola acaba por subordiná-la ao discurso científico-pedagógico, quando não por aniquilá-la.

Literatura; escola; ciência; discurso; prazer

LITERATURE FOR BEARING THE LETTER

This article aims to discuss the function of literature, mainly when it is proposed as an activity in schools, on the basis of some inferred conceptions of discourse and subject of Psychoanalysis. After taking the assumption that the literature differentiates from science exactly because it considers itself as discourse, I conclude that when the literature is taken by the lens of the so called teaching metho$d s$, the school subordinates the literature to the scientific-pedagogical discourse and the school might aniquilated it.

Literature; school; science; discourse; pleasure

\section{LITERATURA PARA LITERATURAR}

$\mathrm{M}$ eus estudos sobre a temática linguagem, educação e psicanálise levaram-me a pensar e a discutir, por algumas vezes, a função da literatura, principalmente a função da literatura quando se a propõe como atividade nas escolas. Por exemplo, nas disciplinas que leciono para os alunos de Pedagogia, esse assunto já suscitou boas e instigantes discussões.

No entanto, às vezes, quando convidado para falar sobre esse tema, vejo-me diante da idéia de estar penetrando num campo complexo, que ainda merece de minha parte estudos mais aprofundados. Por outro lado, porque minha temática sempre tem a ver com as concepções de linguagem, discurso e sujeito, acredito poder encadear algo que possa travar, talvez, bons diálogos com os que pensam especificamente a literatura. É o que tentarei fazer neste artigo.

Desde quando comecei a articulá-lo, de uma coisa eu tinha certeza: meu título seria "Literatura para ....". Só não sabia para o quê. Literatura para abrir a possibilidade do novo, para fugir da mesmice, para fugir do efêmero; literatura para constituir singularidades, para convocar sentimentos afetivos; literatura para quebrar a lógica racional, para enver-

Doutor em Lingüística, Professor da Faculdade de Educação e do Programa de Pós-graduação em Educação da Universidade Federal de Goiás. 
gar uma língua constituída; literatura para ... Não era possível mesmo fechar minha frase.

Todas essas possibilidades tinham uma certa relação com esta outra meia frase que me vinha à cabeça: literatura não para... E para completá-la, lembravam-me vários sintagmas já articulados em minha constante crítica ao discurso pedagógico vigente. Literatura não para ajudar o aluno a construir conceitos científicos. Literatura não para conscientizar o cidadão de seus direitos e deveres. Literatura não para divulgar uma concepção de homem e de mundo politicamente corretos. Literatura não para respeitar a liberdade e a autonomia do aluno.

Enfim, num certo momento de minha elaboração, depareime com "Literatura para literatar". Daí em diante, pouco a pouco, vim tentando dar conta desse "literatar", ou seja, vim pensando o que de fato ele pode nomear na abrangência dessa discussão. Se, por um lado, ele pode parecer muito bonito - pois nos lembra atar a litera, ou atar alguma coisa de real para um sujeito pela força da letra - por outro, não podemos esquecer que literatar, literataço, literatagem, literatice... nos remetem ao que costumam dizer sobre uma certa literatura ruim ou ridícula, à mediocridade que costumam fazer sob o termo literatura.

Lacan (1971), na lição sete de seu seminário denominado De um discurso que não seria do semblante, para falar da questão que nos interessa aqui, escolheu o termo "lituraterre" ("lituraterra" em Português). Isso nos desloca do "literatar" para o que há de litura na litera; litura, que segundo o Aurélio (Ferreira,1986) significa rasura, que por sua vez nos remete a "palavra(s) riscada(s) ou raspada(s) de modo que sua leitura se torne impossível".

Se, para sua identificação fundamental, o sujeito se apóia num céu constelado, num semblante a que nos leva cotidianamente o encadeamento significante, a litera, para além dessa função de referência, convoca esse sujeito a se haver com o traço unário de sua identificação. Em vez de se situar no embarrancamento que um dicionário ou uma gramática são capazes de promover por força de uma escrita já estabelecida historicamente, essa letra litura. Ela apaga a barra que barrou o $S_{1}$, voltando com o sujeito à perda original, ao desconforto e ao vacilo que o constituíram.

Deparamo-nos, portanto, com a necessidade de distinguir letra de significante. Como nos diz Lacan (lição de 12/05/1971): "entre centro e ausência, entre saber e gozo, há litoral que não vira para o literal senão se vocês pudessem tomar a mesma viragem a todo momento. É somente por isso que vocês podem se considerar como agentes que a sustentam. O que se revela de minha visão de resplendor, isso que domina a rasura, é que, ao se produzir de 
entre as nuvens que Aristófanes me chama para encontrar o que é do significante, ou seja, o semblante por excelência, se é de sua ruptura que chove esse efeito, ao se precipitar o que aí era matéria em suspensão."

Se em nossa comunicação cotidiana nos tomamos como agentes de nosso discurso - e isso nos sustenta como cidadãos críticos, conscientes, centrados em boas causas, a despeito é claro do tanto que escondemos, inclusive de nós mesmos, nossas angústias - na literatura somos convocados a aturar nosso lugar de objeto. Se a questão é litura aturar, o barranco simbólico, fundado pela função significante para nos proteger de nosso mal-estar e de nossa falta de origem, aplaina-se num traço. A letra nos desloca de nossa estruturação esférica para o desfiladeiro.

Umberto Eco (2001, p. 3) comenta, em seu artigo "A literatura contra o efêmero", que ler uma história é se deparar com a descoberta de que as coisas acontecem sempre, de certo modo, à margem do desejo do leitor, que "deve aceitar essa frustração e, por meio dela, sentir o tremor ante o Destino". É interessante trazer aqui esse Eco, pois sei que ele assusta bem menos do que Lacan, mesmo quando nos diz que as histórias já feitas nos ensinam também a morrer, que "essa educação para o fado e para a morte é uma das principais funções da literatura".

"Literatura para literaturar" marca, portanto, sua diferença com relação à "Literatura para literatar". Tomemos, para ilustrar a linha do discurso que me interessa sustentar aqui, a fala simples, mas bem articulada a partir daquilo que tentei pro-mover como ensino numa das disciplinas do curso de Pedagogia, "Língua Portuguesa: metodologia e conteúdo". Ela me chegou às mãos, numa avaliação de final de bimestre, como o resultado do que eu havia proposto num dos itens do programa de curso sob o título "Conhecer e identificar as tendências que fundamentam o trabalho com a literatura".

Eis alguns trechos: “... é inevitável a tentação de dar uma função à literatura, seja de fazer a interdisciplinaridade, seja de formar cidadãos, construir conceitos ou tornar as aulas prazerosas. Já estou mesmo acostumada a atribuir função à literatura e nem me apercebia disso. Logo eu, que amo tanto os mistérios das palavras e a deliciosa confusão de significantes e significados que se entrelaçam em nossas mentes com a leitura, peguei-me ali, no dia-a-dia, usando a literatura apenas para ensinar a preservar o meio ambiente ou para trabalhar conteúdos de história. Aos poucos... fui percebendo... que as minhas leituras passam a constituir o meu ser, a marcar as minhas escolhas. Tudo o que eu sou, tudo o que eu me tornei é produto do que eu li e acrescentei às minhas experiências pessoais. 
Cada leitura acrescenta em mim um pouco do que o autor quis dizer, do que eu consegui ver e, principalmente, um pouco de si mesma, do que ela é capaz de provocar enquanto arte, incontrolável e imprevisível a todos nós..." (Osório, 2004, pp. 2-3).

Eu gostei do modo como essa aluna se confessou ter passado pela "provinha" a que a submeti, pois a vi ali em seu texto marcada pelas vozes que circularam em nossas aulas e, ao mesmo tempo, procurando escapulir do precipício em que alguns questionamentos a colocaram. Várias ressonâncias se entrelaçaram para compor essa rede em que ela se apresenta.

Graça Paulino, Sônia Kramer e Roland Barthes. Esse foi o percurso que preparei para apresentar aos alunos tanto os paradoxos dos que pensam um trabalho com a literatura na escola quanto algumas possibilidades de subverter a instrumentalização, o mecanicismo e o positivismo com que a cercam. Sintetizo para vocês esse caminho que trilhamos.

Paulino (1999), ao falar de leitura literária como experiência artística, convoca "Ismália", de Alfhonsus de Guimaraens, para provocar aqueles que ela chama de "os práticos". Ismália enlouquecida na torre diante de duas luas, uma no céu, outra no mar toma uma decisão de anjo: "as asas que Deus the deu ruflaram de par em par... sua alma subiu ao céu. Seu corpo desceu ao mar..." (Guimaraens, apud Paulino, 1999, p. 55).

Em vez de propor uma leitura funcional que prepararia o cidadãoleitor para se defender das condições indignas de sobrevivência, ela se ima- gina lendo esse poema com seus alunos de 4a. série. Tratar-se-ia de ir mudando o jeito de falar dos sonhos, de mostrar que a poesia pode ir-se fazendo de inúmeras maneiras. Tratar-se-ia ainda, conforme sua justificativa, de possibilitar que a criança desenvolva "o gosto e as habilidades próprias da leitura literária", para que ela possa ser capaz, quando sair da escola, de ler além dos textos didáticos e informativos.

Isso seria litura aturar, se eu os poupasse dos paradoxos, dos escorregões, a que Paulino também está sujeita. Não vou deter-me neles. Convido-os para essa leitura, ou releitura, se for o caso. Vou apenas destacar aqui um trechinho em que as coisas se ajeitam num mar de rosas, conforme o discurso que tomamos hoje como científico, sob o rótulo da linguagem-comunicação: "se levarmos a sério o fato de que os textos são processos de comunicação que só se completam na interlocução, a leitura literária torna-se fundamental para que esse uso literário da língua realmente se concretize na sociedade..." (Paulino, 1999, p. 57).

Andemos um pouquinho agora com Kramer (2000), que, a partir de entrevistas com professores sobre a relação deles com a escrita e com a leitura, propõe-se a entendêlas como experiência. Com base nos ensaios de Walter Benjamin, ela distingue essa experiência daquilo que seria apenas vivência, dizendo que esta última é finita, pois se esgota no momento mesmo de sua realização, enquanto que a experiência, por se constituir numa ação compartilhada, contada a um outro, torna-se infini- 
ta. Leitura e escrita como experiências são, portanto, ações que passam para além do seu tempo de realização; ações que convocam também o papel da memória para não se desprezar o passado quando se propõe a se indagar sobre o futuro ou o presente.

A leitura literária é entendida, nesse contexto, como uma possibilidade de se resgatar a produção cultural crítica, capaz de contribuir para a formação de leitores e escritores, capaz de abrir-lhes um espaço de indignação e resistência perante o legado de barbárie que a ciência e a tecnologia vêm produzindo. A literatura tem, portanto, segundo Kramer, o papel central de humanizar; o papel de se contrapor a outras produções, também ditas culturais, que desumanizam.

Literatura para humanizar o humano, ou aquele que não seria, antes dela, propriamente humano. Bastaria que nos deparássemos nessa noção de humano para puxarmos várias outras leituras disso que Kramer nos apresenta sob esta redundância contraditada a que ela dá destaque em seu subtítulo : "formação de sujeitos sociais".

Será por que que as aulas propostas culminaram em Barthes? Porque ele, sim, compatível com o que já apresentei aqui, com Lacan (1971), desloca a função da literatura de seus rumos bem definidos para nos apresentá-la como rumor. O que a ciência tem que a literatura não tem? $\mathrm{O}$ estatuto, ele responde. $\mathrm{E}$ a literatura precisa correr atrás desse estatuto, como pretendeu o estruturalismo? Não! Seu papel, segundo ele, é "representar ativamente à instituição cien- tífica aquilo que ela recusa, a saber, a soberania da linguagem" (Barthes, 1988, p. 29, grifo do autor).

O que está em questão, para Barthes, é uma terceira margem, a do prazer, o Eros da linguagem, de que o discurso científico está longe. Prazer (jouissance), para Barthes (1996), é isto: sustentar a imprevisão do desfrute, a intermitência entre aparecimento-desaparecimento; jamais se explicar, pois o lugar da dúvida não deve ser tamponado por uma explicação "iluminada". Para Lacan, jouissance (traduzido em português por gozo) tem a ver com o fato de nós humanos habitarmos a linguagem e, por isso, experimentarmos um modo de gozar diferente daquele que podemos supor nos animais.

É isto que a literatura tem que a ciência não tem: a literatura se assume como discurso. Enquanto que, "para a ciência, a linguagem não passa de um instrumento, que se tem interesse em tornar tão transparente, tão neutra como possível, submetida à matéria científica (operações, hipóteses, resultados) que, ao que se diz, existe fora dela e a precede" (Barthes, 1988. p. 24), para a literatura a linguagem é o seu próprio mundo; toda a literatura está contida no ato de escrever, na escritura. Uma coisa é pensar, dizer como verdade; outra coisa é litura aturar.

Concluo com essa volta ao título tão demoradamente pensado para este artigo, ou seja, com esse possível preenchimento para o sintagma vazio do "Literatura para ...", que foi o que me movimentou neste meu discurso. Espero, com isso, tê-los levado a articular algumas pas- 
sagens possíveis do literatar para o literaturar; espero tê-los levado pelo menos à desconfiança de que tomar a literatura pela lente dos chamados métodos de ensino implica sua "desfunção", sua subordinação ao científico-pedagógico, quando não seu aniquilamento.

\section{REFERÊNCIAS BIBLIOGRÁFICAS}

Barthes, R. (1988). Da ciência à literatura. In $O$ rumor da língua. São Paulo: Brasiliense, pp. 23-29.

(1996). O prazer do texto (4a. ed.). São Paulo: Perspectiva.

Eco, U. (2001, 18 de fevereiro). A literatura contra o efêmero. O Popular. Goiânia/GO.

Ferreira, A. B. O. (1986). Novo dicionário Aurélio: língua portuguesa. Rio de Janeiro: Nova Fronteira.

Kramer, S. (2000). Leitura e escrita como experiência: seu papel na formação de sujeitos sociais. Presença pedagógica. V. 6, n. 31, jan./fev, 17-27.

Lacan, J. (1971). De um discurso que não seria do semblante. - seminário inédito, tradução provisória do Centro de Estudos Freudianos do Recife.

Osório, J. L. (2004). Para que serve a literatura? Goiânia/GO: Faculdade de Educação da UFG [texto escrito em sala de aula].

Paulino, G. (1999). Para que serve a literatura infantil? Presença pedagógica. V. 5, n. 25, jan./fev, 51-57.

Recebido em abril/2005.

Aceito em maio/2005. 